\title{
The Effect of Copper and Manganese on the Amorphization Process in a Thin Fe-Si-Mg-O Film
}

\author{
A. S. Yurovskikh', N. N. Nikul'chenkov¹, A. A. Redikultsev'1 , Z. Z. Lutfieva ${ }^{1}$, and \\ M. L. Lobanov ${ }^{1,2}$ \\ ${ }^{1}$ Ural Federal University, 19 Mira St., Yekaterinburg, 620002, Russia \\ ${ }^{2}$ Institute of Metal Physics, Ural Branch of RAS, 18 Kovalevskoi St., Yekaterinburg, 620990, Russia
}

\section{Abstract}

The effect of copper and manganese on the amorphization process in the surface layer of a technical Fe-3\% Si alloy during annealing in the $\alpha \rightarrow \gamma$ transition temperature range was determined by $\mathrm{x}$-ray phase analysis. The presence of $0.5 \mathrm{wt}$. \% $\mathrm{Cu}$ and $0.3 \mathrm{wt}$. \% $\mathrm{Mn}$ in the initial Fe-3\% Si solid solution significantly enhances the amorphization process that occurs when heated in the temperature range $920 \ldots 960^{\circ} \mathrm{C}$ as an alternative to the $\alpha \rightarrow$ $\gamma$ phase transformation. The effect of amplification of amorphization is both in obtaining a larger amount of material in the amorphous state, and in the appearance of two amorphous phases, differing in average interatomic distance. The composition of the amorphous phase is approximately described as $\mathrm{Fe}_{89} \mathrm{Si}_{6} \mathrm{Mg}_{4} \mathrm{Mn}_{0.5} \mathrm{Cu}_{0.5}$ in the presence of $\mathrm{Cu}$ and $\mathrm{Mn}$ atoms and $\mathrm{Fe}_{90} \mathrm{Si}_{6} \mathrm{Mg}_{4}$ in the case of their absence in the amorphous layer.

Received: 25 February 2019

Accepted: 9 April 2019

Published: 15 April 2019

Publishing services provided by Knowledge E

(c) A. S. Yurovskikh et al. This article is distributed under the terms of the Creative Commons Attribution License, which permits unrestricted use and redistribution provided that the original author and source are credited.

Selection and Peer-review under the responsibility of The Ural school-seminar of metal scientists-young researchers Conference Committee.

\section{Introduction}

Since the discovery in 1960 of metallic glass [1], amorphous materials have become a completely new class of metallic alloys, the annual production and use of which is measured in thousands of tons. The progress noted is primarily due to the high level and / or unique combinations of a number of structurally dependent physical properties (primarily magnetic and mechanical) of alloys in an extremely disordered structural state [2]. The theory explaining the formation of the atomic structure and its connection with the properties of metallic glasses has been the subject of scientific research to date. Despite the quite a large number of currently known chemical compositions of amorphous metal glasses, interest in developing new ones or optimizing the composition of known ones continues to grow [2-6]. It is important to emphasize that all technologies for producing amorphous materials imply ultrahigh cooling rates, for "freezing" atoms in a metastable structure that does not have a long-range order. The implementation 
of such speeds, especially for massive samples, creates great difficulties in industrial production. In addition, the apparent instability of amorphous metallic materials during heating significantly limits the scope of their application.

In the study of processes occurring on the surface of the alloy Fe-3\% Si-0.5\% Cu with a heat-resistant $\mathrm{MgO}$ coating $[7,8]$ during continuous high-temperature annealing (HTA) in the temperature range $600 \ldots 1060^{\circ} \mathrm{C}$, the formation of an amorphous phase in the form of solid solution based on Fe was established by non-ambient XRD [9]. The effect was observed in the layer consisting of $\alpha-\mathrm{Fe}$ and $(\mathrm{MgFe})_{2} \mathrm{SiO}_{4},(\mathrm{MgFe}) \mathrm{O}, \mathrm{SiO}_{2}$ oxides when heated in the temperature range corresponding to the $\alpha \rightarrow \gamma$ transformation: 920... $960^{\circ} \mathrm{C}$. The amorphous state of the thin layer was preserved during further annealing, both with an increase in temperature and with cooling down to $20^{\circ} \mathrm{C}$. The fact of the formation of the amorphous state of a solid solution of $\mathrm{Mg}$ in $\mathrm{Fe}-\mathrm{Si}-\mathrm{Cu}$ using the pretransition state of the $\alpha \rightarrow \gamma$ transformation was established. This effect is explained by a significant increase in the solubility of $\mathrm{Mg}$ (practically insoluble in Fe crystal lattices) in a solid solution which are in the pretransition state near the phase transition point. It is important to note that the use of such a method for producing amorphous structures in metallic materials (without using ultra-high cooling rates of the liquid phase) opens up new possibilities for obtaining massive samples and products with unique properties, including magnetic ones.

The aim of this work was to study the effect of $\mathrm{Cu}$ and $\mathrm{Mn}$ contained in the initial solid solution based on $\mathrm{Fe}-3 \% \mathrm{Si}$ on the effect of amorphization in the surface oxidized alloy layer.

\section{Research Methods}

To study the effect of the initial composition on the amorphization process, $\mathrm{Fe}-3 \% \mathrm{Si}$ and $\mathrm{Fe}-3 \% \mathrm{Si}-0.5 \% \mathrm{Cu}-0.3 \% \mathrm{Mn}$ alloys were used. Industrial samples were taken after the HTA of electrical anisotropic steel coated with heat-resistant coating. They consisted of a ferromagnetic base of Fe-3\% Si and a ground layer (Glass Film), formed due to the interaction of $\mathrm{MgO}$ with the surface of the material during the HTA [8].

X-ray phase analysis of the sample surface was performed on a Bruker D8 Advance diffractometer in $\mathrm{K} \alpha$ Co radiation using the AntonPaar HTK1200N high-temperature chamber. The diffraction patterns were taken in isothermal conditions with a step of $50^{\circ} \mathrm{C}$ in the temperature range of $20-1050^{\circ} \mathrm{C}$.

The composition of surface layer was studied using a GDA-750 (glow discharge analyzer) instrument $[8,10]$. This instrument allows precise determination of the chemical 
composition for all alloying elements except hydrogen, nitrogen and carbon with the accuracy of $\pm 10 \%$. The results of the survey are reproduced in the form of the distribution of alloying elements depending on the depth of penetration into the sample, which ranges from several nanometers to 200 microns (in increments of $\sim 0.5 \mathrm{~nm}$ ). Instrument allows investigating the chemical composition and thickness of virtually any steel coating and determining the integral characteristics of the chemical composition at a given depth.

\section{Results and Discussion}

X-ray phase analysis of both types of samples showed (Fig. 1) that a comparatively small amount of the amorphous phase is observed in the low-temperature region; it increases with the future heating. The maximum amount of the amorphous phase is fixed at temperatures above the austenitization of pure Fe $\left(950-1050^{\circ} \mathrm{C}\right)$. With further cooling, the amount of the amorphous phase decreases to a minimum level, approximately corresponding to the initial state.

At a temperature of $920^{\circ} \mathrm{C}$, slightly exceeding the temperature of a possible $\alpha \rightarrow \gamma$ transition in Fe, a sample without $\mathrm{Cu}$ (Fig. 1, a, b) experienced a large jump in the amount of the amorphous phase, unlike the sample with $\mathrm{Cu}$ (Fig. 1, d, f), where the change in the amount of the amorphous phase occurred more smoothly. In addition, in the presence of $\mathrm{Cu}$ in the initial solid solution, the halo corresponding to the amorphous phase acquired a bimodal character starting from a temperature above $700^{\circ} \mathrm{C}$, divided into a two halos (Fig. 1, d, f) with maxima at 49.5 and $53.5^{\circ}$ on a $2 \theta$ scale. In fact, we can assume the appearance of two amorphous phases, differing in the average interatomic distance. During cooling, processes that reverse heating occurred (Fig. 1, a, d, c, f) - the halo bimodality almost disappeared at temperatures below $800^{\circ} \mathrm{C}$; moreover, the lower the temperature, the smaller the amount of the amorphous phase was observed.

There is a smooth change of the types of oxide phases from $(\mathrm{MgFe}) \mathrm{O}$ and $(\mathrm{MgFe})_{2} \mathrm{SiO}_{4}$ to $(\mathrm{MgFe})_{2} \mathrm{SiO}_{4}$ and $\mathrm{SiO}_{2}$ in the surface layer formed as a result of HTA. According to GDOS analysis data, this allows to isolate a narrow layer where forsterite $(\mathrm{MgFe})_{2} \mathrm{SiO}_{4}$ is in equilibrium with the solid solution (amorphous phase) (Fig. 2). The size of this layer according to the GDOS analysis is $0.75 \ldots 0.95$ microns. Assuming that the Fe-based solid solution contains almost no oxygen atoms, the chemical composition of the amorphous phases was defined as the concentration of all atoms in the layer minus the atoms that make up the forsterite. The composition of the amorphous phase is approximately 
described as $\mathrm{Fe}_{89} \mathrm{Si}_{6} \mathrm{Mg}_{4} \mathrm{Mn}_{0.5} \mathrm{Cu}_{0.5}$ in the presence of $\mathrm{Cu}$ and $\mathrm{Mn}$ atoms and $\mathrm{Fe}_{90} \mathrm{Si}_{6} \mathrm{Mg}_{4}$ in the case of their absence.
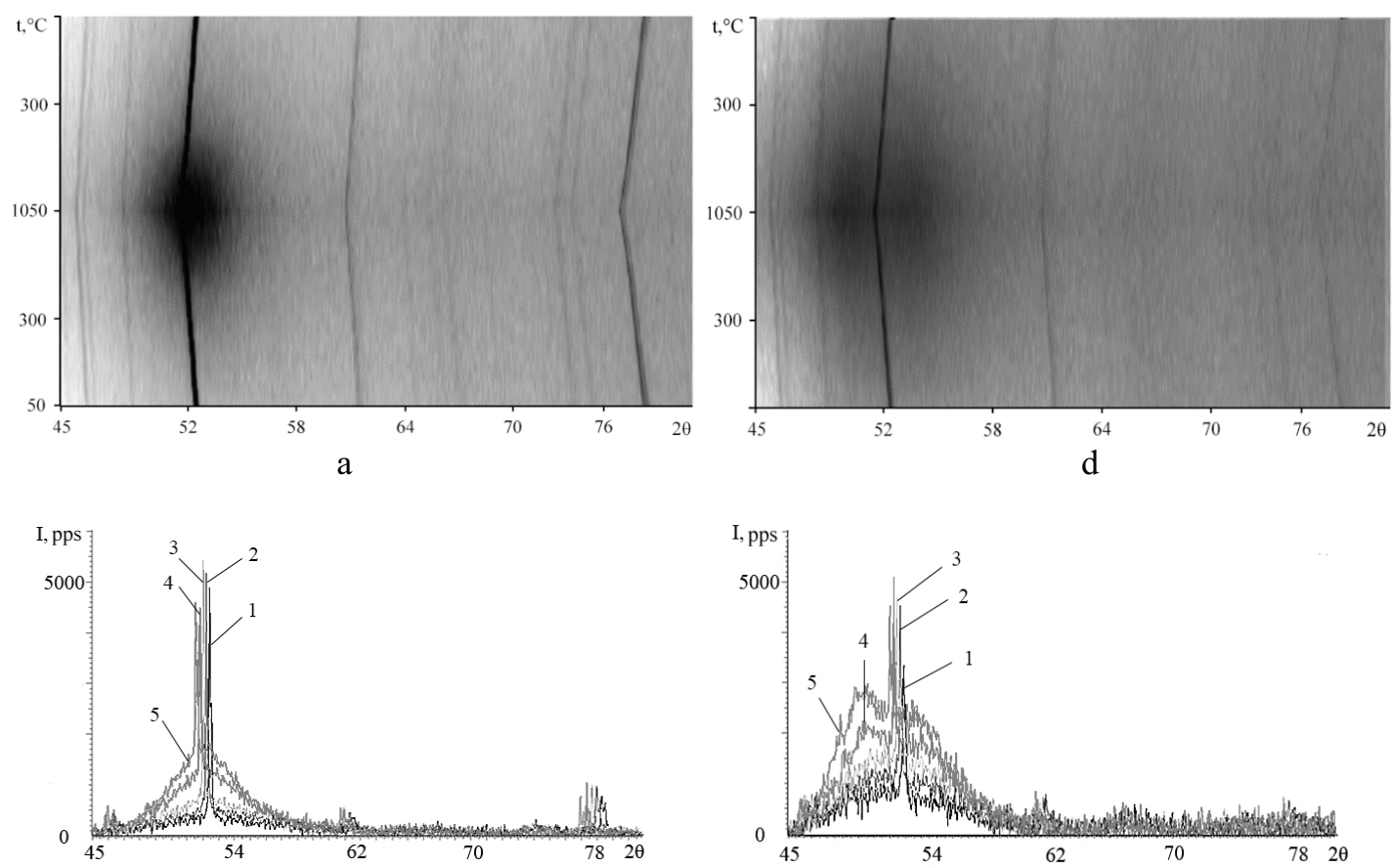

$\mathrm{b}$

e
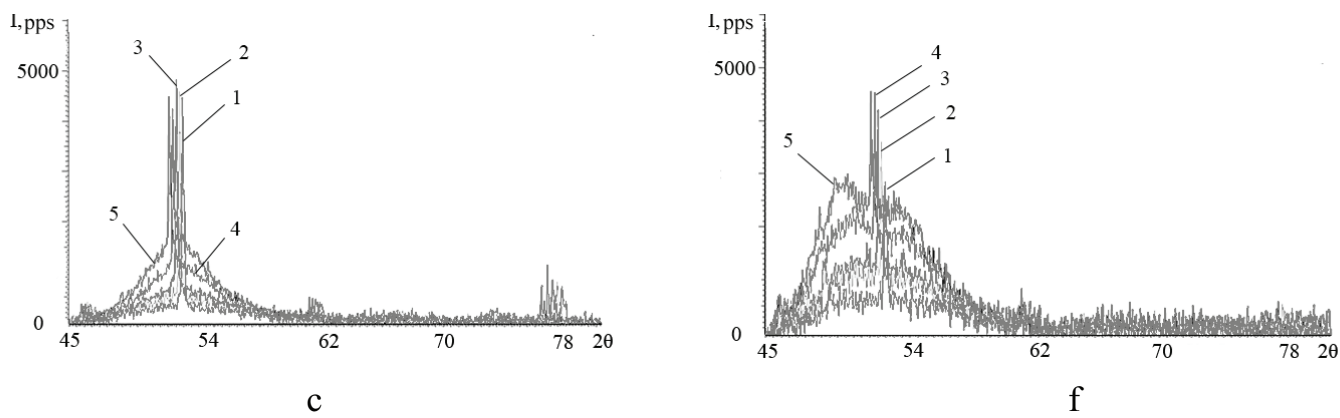

Figure 1: Diffraction patterns of Fe-3\%Si (a, b, c) and Fe-3\%Si-0.5\%Cu-0.3\%Mn (d, e, f) alloys while heating (b, e) and cooling (c, f); $1-50^{\circ} \mathrm{C}, 2-300^{\circ} \mathrm{C}, 3-550^{\circ} \mathrm{C}, 4-800^{\circ} \mathrm{C}, 5-1050^{\circ} \mathrm{C}$.

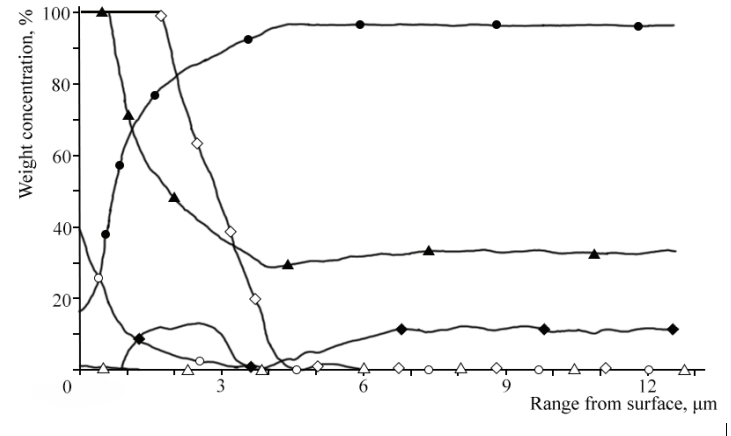

a

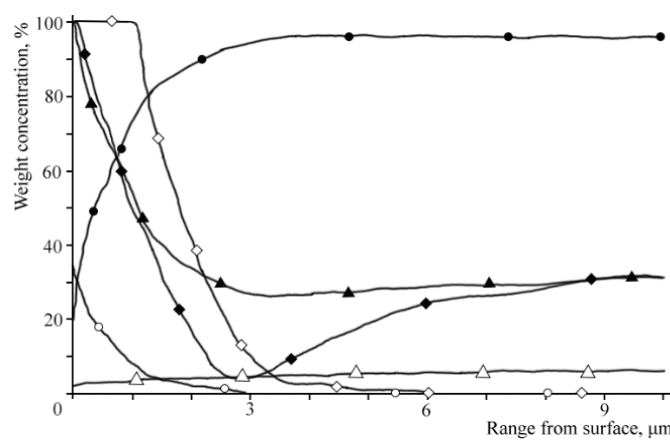

b

Figure 2: Surface layers composition after heating to $1050^{\circ} \mathrm{C}$ with subsequent cooling (GDOS): a - Fe-3\%Si;

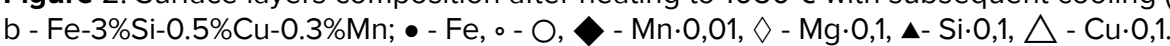




\section{Summary}

1. It is shown that the presence of $0.5 \mathrm{wt} . \% \mathrm{Cu}$ and $0.3 \mathrm{wt}$. \% $\mathrm{Mn}$ in the initial Fe-3\% Si solid solution significantly enhances the amorphization process, which occurs when heated in the temperature range of $920 \ldots 960^{\circ} \mathrm{C}$ as an alternative to $\alpha \rightarrow$ $\gamma$ transformation. The effect of amplification of amorphization is both in obtaining a larger amount of material in the amorphous state, and in the appearance of two amorphous phases, differing in average interatomic distance.

2. The approximate compositions of the amorphous phases were established: $\mathrm{Fe}_{89} \mathrm{Si}_{6} \mathrm{Mg}_{4} \mathrm{Mn}_{0.5} \mathrm{Cu}_{0.5}$ in the case of the presence of $\mathrm{Cu}$ and $\mathrm{Mn}$ atoms, and $\mathrm{Fe}_{90} \mathrm{Si}_{6} \mathrm{Mg}_{4}$ in the case of their absence.

\section{Acknowledgments}

The work was done using the equipment of the laboratory of Structural Methods of Analysis and Properties of materials and nanomaterials of the Collective Use Center affiliated to Ural Federal University. The study was supported by the program of increasing the competitiveness of the leading Russian universities, RF Government resolution No. 211, contract No. 02.A03.21.0006. The reported study was funded by RFBR according to the research project № 19-08-00071.

\section{References}

[1] W. Klement Jun, R. H. Willens and P. Duwez, Non-crystalline Structure in Solidified Gold-Silicon Alloys, Nature. 187 (1960) 869-870.

[2] A. Inoue, A. Takeuchi, Recent development and application products of bulk glassy alloys, Acta Materialia, 59 (2011) 2243-2267.

[3] A. H. Hunter, V. Araullo-Peter, M. Gibbons, and at al., Three-dimensional imaging of shear bands in bulk metallic glass composites, Journal of Microscopy. 00. Issue (2016) $1-7$.

[4] V. Schnabel, D. Music, W. J. Clegg, and at al., Ultra-stiff metallic glasses through bond energy density design, Journal of Physics Condensed Matter. No 3 (2017) 1-28.

[5] B. Zang, R. Parsons, K. Onoder, and at al., Effect of heating rate during primary crystallization on soft magnetic properties of melt-spun Fe-B alloys, Scripta Materialia. 132 (2017) 68-72. 
[6] K. Suzuki, R. Parsons, B. Zang, and at al., Copper-free nanocrystalline soft magnetic materials with high saturation magnetization comparable to that of Si steel, Applied Physics Letters. 110 (2017) 0124407.

[7] M. L. Lobanov, A. I. Gomzikov, S. V. Akulov, and at. al., Decarburizing annealing of technical alloy Fe-3\%Si / Metal Science and Heat Treatment. 47, No 9-10 (2005) 478483.

[8] M. L. Lobanov, A. S. Yurovskih, Thermochemical Treatment of Anisotropic Electrical Steel, Metal Science and Heat Treatment. 58 (2017) 667-673.

[9] Z. Z. Lutfieva, E. V. Luk'yanova, A. S. Yurovskikh, High-temperature amorphization of Fe-Si-Mg-O thin foils of the system, Ural School of Metal Scientists of Young Scientists. Yekaterinburg: UrFU. (2016) 309-313. (in russ.).

[10] S. Jung, M. S. Kwon, J. Park, and at. al., A TEM Study of Oxide Layers Formed during Decarburization Annealing of Electrical Steel, ISIJ International. 51 (2011) 1163-1168. 